\title{
Using Learning Styles to Enhance Learning Management Systems
}

\author{
M. Prabhani Pitigala Liyanage, K. S. Lasith Gunawardena, Masahito Hirakawa
}

\begin{abstract}
Learning management systems (LMSs) are becoming increasingly popular at many educational institutions such as universities. However, they provide same content for all learners in a given course. Educational theory suggests that learners have different styles of learning. Ideally, the content must be arranged to match each learner's learning style. In this study, we propose a framework for adaptive LMSs that can tailor course content to the individual learner's learning style. We estimate the learning style of the student using two methods: a questionnaire and a rule-based method that utilizes the learner's activity within the LMS. The Felder-Silverman learning style model served as the basis for our system implementation. We explain the operational aspects of our framework and present the findings in applying the framework to a course conducted in Moodle LMS.
\end{abstract}

Keywords-e-learning, Learning Management Systems, Learning Styles, Moodle, Adaptive Learning Management Systems

\section{INTRODUCTION}

$\mathrm{U}$ niversal, equal access to education is a virtue of a utopian society. Access to education facilities and literacy rate are considered to be important indicators of a country's development in the knowledge economy. A wholesome life is essentially built upon proper skills, attitudes, and knowledge obtained via formal education.

With the dawn of the electronic age, technology has permeated the traditional classroom in several ways. Electronic learning (e-learning) has come a long way since the early days of electronic aids and television broadcasts. The Internet paved the way for making the physical distance barrier in access to education irrelevant. This breakthrough has enabled universities to welcome learners from all over the world. People interested in courses can experience quality teaching, access learning materials, and undertake fee-levying regular courses via distance learning mode. Massive Open Online Courses represent one such recent addition to the e-learning space.

Two main issues must be addressed in the implementation of an e-learning infrastructure: the e-learning software platform and the digital content developed to suit the platform. Learning management systems (LMSs) are a key category of software platforms used currently. An LMS is a software application or Web-based technology used to plan, implement, and assess a

Manuscript received Feb, 15, 2014. Recommended by Dr. Hakim Usoof on June 10, 2014.

M. Prabhani Pitigala Liyanage, K. S. Lasith Gunawardena, Masahito Hirakawa are with Interdisciplinary Graduate School of Science and Engineering, Shimane University 1060 Nishikawatsu-cho, Matsue-shi, Shimane, Japan (research@prabhani.com, research@lasith.com, hirakawa@cis.shimane-u.ac.jp) specific learning process [1]. Modular Object Oriented Developmental Learning Environment (Moodle) [2], Blackboard [3], and Sakai [4] are some of the leading systems. Among these, Moodle is probably the most common, with over 68,000 sites serving over 67 million users in 235 countries [2]. Reasons for its wide application include the ability to run on different infrastructure platforms and the cost of ownership factor. As an open source product, Moodle also enables third-party enhancement of its functionality by the addition of modules.

Despite the openness of such platforms, digital contents are offered in the same format to all learners within a particular course. LMSs tend to be course centric rather than learner centric. This inability to personalize learning is often regarded as a limitation of most current LMSs, as noted by Graf and List [5]. Issues requiring attention to cope with this problem include learner expectations, motivation, and learning style [6]. Diverse efforts to enhance the learning experience when using LMSs are already appearing. The ability to personalize LMSs with style templates and language is one approach. Another is the use of sharable content object reference model (SCORM) standards, which enable interoperability, accessibility, and reusability of Web-based content.

Additionally, adaptivity in learning support systems has different interpretations. Graf [5] stated that LMS adaptivity indicates all manner of automatic adaptation to individual user needs, including personal annotations of learning objects or automatically adapted content.

De Crook et al. identified the following characteristics of adaptive systems [7].

1. Information should adapt to what a learner already knows (prior knowledge) or can do (prior skill).

2. Information should adapt to a learner's learning capabilities.

3. Information should adapt to a learner's learning preferences or style.

4. Information should adapt to a learner's performance level and knowledge state (i.e., the system should provide feedback).

5. Information should adapt to a learner's interests.

6. Information should adapt to a learner's personal circumstances (location, tempo, etc.).

7. Information should adapt to a learner's motivation.

Adaptive quizzes in LMSs comprise a trial that covers items 1 and 4 in De Crook's classification. Moodle supports a quiz feature that can adapt to the learning situation, giving hints 
before asking the learner to try again [2]. Newer versions of Moodle (2.0 upward) support conditional activities, for example, after a student passes a quiz, it enables the next lesson.

Educational theorists have presented several models for classifying a learner's learning style. Among these, the Felder-Silverman learning style model (FSLSM) [8] has been applied in e-learning environments. In this model, a learner's learning style is categorized in four dimensions, each formed by a pair of distinct preferences: active-reflective, sensing-intuitive, sequential-global, and visual-verbal.

Several recent studies have attempted to address the issue of identifying learning styles to personalize the learning experience [9], [10]. These studies have adopted statistical as well as simple rule-based approaches. An important factor to consider here is that an individual learner's learning style may vary because of factors beyond the control of the course or the LMS. Thus, the system must be capable of dynamically responding to such situations.

In this study, we present a framework that assists the learner to efficiently and effectively complete the learning activities by adaptively changing the course material provided in the Moodle LMS. In our framework, we introduce three separate entities created as Moodle modules.

The first module uses a well-established questionnaire, the Index of Learning Styles (ILS) [11], to evaluate a learner's learning style. In addition the same module estimates the learner's learning style using activities performed by the user in the LMS. This enables the storing of a learner profile within the LMS. Moodle log data pertaining to user activities such as the number of visits to learning material of each type and the duration spent on each material constitute this estimation, which uses rules presented by Graf et al. [12]. We also introduce the concept of a learning styles map, a graphical representation of the learning preference based on the FSLSM, which can be beneficial in an instructor's analysis of students' learning styles.

In the second module, course content is recommended to the learner based on his/her learning profile. The basis for this recommendation is a simple rule-based method.

The third module enables instructors to fine tune the recommendation. The current implementation adopts numerical thresholds assignment for this purpose.

To test our framework, we set up a Moodle LMS in two educational establishments in Sri Lanka and prepared learning materials to match learning preferences. Our study reveals that the system is comparable with previous studies regarding learning profile creation.

This paper proceeds as follows. Section II reviews previous research in this domain. Section III introduces our proposed framework and the methodology. Section IV describes the experiments, results and discussion. Conclusions and future work will be given in Section V.

\section{RELATED WORK}

\section{A. Learning Styles}

Several definitions have been offered for the term "learning style." Honey and Mumford [13] defined it as "a description of the attitudes and behaviors which determine an individual's preferred way of learning." Stewart and Felicetti [14] define learning styles as those "educational conditions under which a student is most likely to learn." A learning-style model classifies students according to where they fit on a number of scales designating the ways in which they receive and process information [9].

Coffield et al. [16] classified learning style models into five families based on fundamental overarching concepts. The first family relates to the concept that learning styles and preferences are largely constitutionally based, including the four modalities: visual, auditory, kinesthetic, and tactile (VAKT). The second family category relates to the concept that learning styles reflect deep-seated features of the cognitive structure, including patterns of abilities. The third considers the learning styles as one component of a relatively stable personality type. The fourth family relates to the concept that learning styles are flexibly stable learning preferences. The last category moves on from learning styles to learning approaches, strategies, orientations, and conceptions of learning [15].

Table 1 reports the five families of learning styles with authors' details and assessment tools for each family and the years of assessment tool introduction [16].

TABLE 1.

FAMILIES OF LEARNING STYLES BY COFFIELD ET AL. [16]

\begin{tabular}{|c|c|c|}
\hline Author(s) & Assessment tool & $\begin{array}{l}\text { Year } \\
\text { introduced }\end{array}$ \\
\hline \multicolumn{3}{|c|}{$\begin{array}{c}\text { Genetic and other constitutionally based learning styles and preferences } \\
\text { including the VAKT }\end{array}$} \\
\hline Dunn and Dunn & $\begin{array}{l}\text { Learning Style Questionnaire (LSQ) } \\
\text { Learning Style Inventory (LSI) } \\
\text { Building Excellence Survey (BES) }\end{array}$ & $\begin{array}{l}1979 \\
1975 \\
2003\end{array}$ \\
\hline Gregorc & $\begin{array}{l}\text { Gregorc Mind Styles Delineator } \\
\text { (MSD) }\end{array}$ & 1977 \\
\hline \multicolumn{3}{|l|}{ Cognitive structure } \\
\hline Riding & Cognitive Styles Analysis (CSA) & 1991 \\
\hline \multicolumn{3}{|c|}{ Stable personality type } \\
\hline Apter & Motivational Style Profile (MSP) & 1998 \\
\hline Jackson & Learning Style Profiler (LSP) & 2002 \\
\hline Myers-Briggs & $\begin{array}{lll}\begin{array}{l}\text { Myers-Briggs } \\
\text { (MBTI) }\end{array} & \text { Type } & \text { Indicator } \\
\end{array}$ & 1962 \\
\hline \multicolumn{3}{|c|}{ Flexibly stable learning preferences } \\
\hline Allison and Hayes & Cognitive Style Index (CSI) & 1996 \\
\hline Herrmann & $\begin{array}{lll}\begin{array}{l}\text { Brain } \\
(\text { HBDI })\end{array} & \text { Dominance } & \text { Instrument } \\
\end{array}$ & 1995 \\
\hline $\begin{array}{l}\text { Honey and } \\
\text { Mumford }\end{array}$ & Learning Styles Questionnaire (LSQ) & 1982 \\
\hline $\begin{array}{ll}\text { Felder and } \\
\text { Silverman }\end{array}$ & Index of Learning Styles (ILS) & 1996 \\
\hline Kolb & $\begin{array}{l}\text { Learning Style Inventory (LSI) } \\
\text { LSI Version } 3\end{array}$ & $\begin{array}{l}1976 \\
1999 \\
\end{array}$ \\
\hline \multicolumn{3}{|c|}{ Learning approaches and strategies } \\
\hline Entwistle & $\begin{array}{l}\text { Approaches to Study Inventory (ASI) } \\
\text { Revised Approaches to Study } \\
\text { Inventory (RASI) } \\
\text { Approaches and Study Skills } \\
\text { Inventory for Students (ASSIST) }\end{array}$ & $\begin{array}{l}1979 \\
1995 \\
2000\end{array}$ \\
\hline Sternberg & Thinking Styles & 1998 \\
\hline Vermunt & Inventory of Learning Styles (ILS) & 1996 \\
\hline
\end{tabular}


Graf [17] identified some of the important learning models in her Ph.D. thesis. These are Myers-Briggs Type Indicator (MBTI) model [18] with four dimensions (extraversion-introversion, sensing-intuition, thinking-feeling, and judging-perceiving) and eight learning styles. All possible combinations can occur, resulting in a total of 16 types.

Gregorc's Mind Styles Model has four learning styles: concrete sequential, abstract sequential, abstract random, and concrete random. Kolb's learning style model [19] theory establishes four distinct learning styles based on a four-stage learning cycle and thus operates on two levels: In the first level, a four-stage cycle exists: Concrete Experience (CE), Reflective Observation (RO), Abstract Conceptualization (AC), and Active Experimentation (AE). In the second level, a four-type definition of learning styles, each representing the combination of two preferred styles, exists. Kolb's model is often easier to represent in a $2 \times 2$ matrix (Table 2 ).

TABLE 2.

KOLB'S LEARNING STYLES IN A $2 \times 2$ MATRIX

\begin{tabular}{|l|l|l|}
\hline \multicolumn{2}{|c|}{ KOLB'S LEARNING STYLES IN A 2 $\times 2$ MATRIX } \\
\hline $\begin{array}{l}\text { Feeling (Concrete } \\
\text { Experience) }\end{array}$ & $\begin{array}{l}\text { Doing (Active } \\
\text { Experimentation) }\end{array}$ & $\begin{array}{l}\text { Watching (Reflective } \\
\text { Observation) }\end{array}$ \\
\hline $\begin{array}{l}\text { Accommodating } \\
\text { (CE/AE) }\end{array}$ & Diverging (CE/RO) \\
$\begin{array}{l}\text { Abstract } \\
\text { Conceptualization) }\end{array}$ & Converging (AC/AE) & Assimilating (AC/RO) \\
\hline
\end{tabular}

Table 2 further highlights Kolb's terminology for the four learning styles: diverging, assimilating, converging, and accommodating. Honey and Mumford's learning style model identifies four learning styles: activists, theorists, pragmatists, and reflectors [20]. The Herrmann "Whole Brain" Model reflects the four quadrants of the brain and their functions, identifying them as quadrant A (left hemisphere, cerebral), quadrant B (left hemisphere, limbic), quadrant C (right hemisphere, limbic), and quadrant D (right hemisphere, cerebral) [17]. Other models include Pask's Serialist/Holist/Versatilist model; Entwistle's Deep, Surface, and Strategic Learning Approach Model; the Grasha-Riechmann participant-avoidant, collaborative learners-competitive learners, and dependent learners-independent learners.

In summary, researchers' development of different models reflects the fact that human thinking and learning behaviors are complex and require further study.

\section{B. The FSLSM}

Although many models have been proposed, the FSLSM proposed by Richard Felder and Linda Silverman is among the most famous models defined by four dimensions, each formed by a pair of distinct characteristics as explained below [8].

The first dimension considers the learner's preferred method of processing information: active (ACT) or reflective (REF). Active learners work well in groups. They do not learn much in situations that require them to be passive and tend to be experimentalists. In contrast, reflective learners work better by themselves or with one other person at most. They do not learn much in situations that provide no opportunity to think about the information being presented and tend to be theoreticians.
The second dimension considers the type of information that the learner preferentially perceives: sensory (SEN) or intuitive (INT). Sensory learners prefer to learn facts and like to relate to practical, real-world situations, whereas intuitive learners prefer abstract learning material such as theories and their underlying meaning. Intuitive learners are more comfortable with symbols than sensory learners.

The third dimension considers the sensory channel through which the learner most effectively perceives external information: visual (VIS) or verbal (VER). Visual learners prefer pictures, diagrams, graphs, or demonstrations, whereas verbal learners prefer spoken information or audio. FSLSM considers no other sensory channels such as touch, taste, and smell as these are relatively unimportant in most educational environments.

The fourth dimension considers how the learner progresses toward understanding: sequentially (SEQ) or globally (GLO). Sequential learners learn in small increments, and therefore have a linear learning progress, tending to follow logical stepwise paths toward solutions. Conversely, global learners use a holistic thinking process and learn in large leaps. They tend to absorb learning material almost randomly without viewing connections; however, after learning sufficient material, they suddenly understand the entire picture. They can solve complex problems and put things together in novel ways, but find it difficult to explain how they did it.

It is noted that, when considering the characteristics of the FSLSM, sequential learners are very much similar to the serial learner type in Pask's model. The opposite of sequential learners, global learners, have the same characteristic as holist learners in Pask's model. The sensing-intuitive dimension of FSLSM has similar characteristics to that of MBTI. In addition, active learners in FSLM have similar features with activist learners in Honey and Mumford model, and accommodating learners in the Kolb's learning styles model. Reflective learners are similar with reflector and diverging learners; Intuitive similar to theorist and assimilating learners, and the sensing learners is related to pragmatist and converging respectively [21].

The FSLSM thus combines several major learning style models but differs from them in considering learning styles as tendencies, indicating that students have a tendency toward a specific learning style but might act differently in some situations. By incorporating the concept of tendencies, the description of learning styles incorporates exceptions and extraordinary situations [17].

Interestingly, the ILS, as developed by Felder and Soloman [11], can be used as an instrument for assessing preferences in the four FSLSM dimensions. This instrument comprises 44 questions, with 11 questions for each dimension. The results of the questionnaire indicate an individual's learning preference in each dimension, with scores ranging from +11 to -11 . This score can be read in the following manner. A score of 1-3 (either plus or minus) indicates that the learner is fairly balanced on the dimension of that scale. A score of 5-7 (either plus or minus) indicates that he/she has a moderate preference for one side of the dimension of the scale, and will more easily learn in a teaching environment that favors that dimension. A score of 9-11 indicates that he/she has a very strong preference for one 
dimension of the scale, and probably has considerable difficulty in learning in an environment that does not support that preference [11].

\section{Finding User Learning Styles in e-Learning}

Since the learning styles models are based on traditional learning, when considering e-learning environments, the types of activities that can be performed by a learner are different. Chang et al. [22] introduced a mechanism that uses the k-nearest neighbor (k-NN) classification and genetic algorithms to classify and identify students' learning styles in a generic model.

It should be mentioned here that the FSLSM is the learning style model most frequently cited with respect to computer-based education systems [16], [17], [23], [24], [25], [26], [27], [28]. One approach in applying the FSLSM has been to utilize the ILS as an online questionnaire to evaluate the learner's learning preferences and recommend appropriate learning material [25], [26], [27]. Savic and Konjovic [26] presented a system that made recommendations using the ILS for a SCORM compliant Sakai LMS, by modifying the organization of the SCORM manifest file. However, all the above systems require students to interrupt their learning to focus on completing a questionnaire.

Özpolat and Akar [29] developed a system that collected learner preference using explicit generic queries. Their system, based on the FSLSM, constructed a learner profile using a conversion unit-based keyword mapping. Furthermore, it built a learner model by processing the learner profile over a clustering unit that used the NBTree classification algorithm in conjunction with a binary relevance classifier.

One limitation of the aforementioned methods is that they do not consider the possibility that the learning style of a learner may vary with time, and subtle changes are possible even during the course of prescribed study. Approaches using more subtle evaluation methods that automatically classify a learner into a preferred learning style have been proposed recently. Most of these have also utilized the FSLSM to identify the learning styles of learners in an LMS. Since most conventional LMSs follow the Content Management System architecture, all student activities such as accessing content and participating in quizzes and forums are recorded in a database log. Nearly, all researchers who follow the data-driven approach use this log data to automatically model students' learning styles.

Protus [28] is a system that recognizes different patterns of learning styles and learners' habits through testing the learning styles of learners and mining their server logs. This system relies on a recommender system that initially processes the clusters on the basis of different learning styles and then analyzes the learners' habits and interests by mining for frequent sequences using the AprioriAll algorithm (collaborative filtering approach). Garcia et al. [9] evaluated the use of Bayesian networks to detect a student's learning style in a Web-based education system.
TABLE 3.

MAPPING ONLINE BEHAVIOR TO FSLSM

\begin{tabular}{|c|c|c|c|c|c|c|c|c|}
\hline \multirow{2}{*}{ LMS Behavior } & \multicolumn{8}{|c|}{ FSLSM Trend } \\
\hline & 总 & $\begin{array}{l}\sum_{0} \\
\frac{0}{4} \\
\stackrel{0}{0} \\
\simeq\end{array}$ & 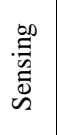 & 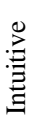 & $\underset{\vec{J}}{\stackrel{\Xi}{>}}$ & $\begin{array}{l}\overline{0} \\
\stackrel{0}{0} \\
>\end{array}$ & 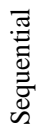 & $\begin{array}{l}\bar{\pi} \\
\frac{0}{0} \\
0\end{array}$ \\
\hline Content visit & - & + & - & + & - & + & & \\
\hline Content stay & - & + & - & + & & & & \\
\hline Outline visit & & & & & & & - & + \\
\hline Outline stay & - & + & & & & & - & + \\
\hline Example visit & & & + & - & & & & \\
\hline Example stay & - & + & + & - & & & & \\
\hline Self-Assessment visit & + & - & + & - & & & & \\
\hline Self-Assessment stay & - & + & + & - & & & & \\
\hline $\begin{array}{l}\text { Self-Assessment twice } \\
\text { wrong }\end{array}$ & + & - & & & & & & \\
\hline Exercise visit & + & - & + & - & & & & \\
\hline Exercise stay & + & - & & & & & & \\
\hline Question detail & & & + & - & & & + & - \\
\hline Question overview & & & & & & & - & + \\
\hline Question facts & & & + & - & & & & \\
\hline Question concepts & & & - & + & & & & \\
\hline Question graphics & & & & & + & - & & \\
\hline Question text & & & & & - & + & & \\
\hline Question interpret & & & & & & & - & + \\
\hline Question develop & & & - & + & & & - & + \\
\hline Quiz revisions & & & + & - & & & & \\
\hline Quiz stay results & - & + & + & - & & & & \\
\hline Forum visit & - & + & & & - & + & & \\
\hline Forum stay & & & & & - & + & & \\
\hline Forum post & + & - & & & - & + & & \\
\hline Navigation skip & & & & & & & - & + \\
\hline $\begin{array}{l}\text { Navigation overview } \\
\text { visit }\end{array}$ & & & & & & & - & + \\
\hline $\begin{array}{l}\text { Navigation overview } \\
\text { stay }\end{array}$ & & & & & & & - & + \\
\hline Irreleva & Beha & & & & & & & \\
\hline Relevant & ositi & Beh & vior & & & & & \\
\hline Relevant & & & avior & & & & & \\
\hline
\end{tabular}


Cha et al. [24] proposed an intelligent learning system with a specific user interface based on the FSLSM. Decision Trees and Hidden Markov model approaches are utilized in this system to predict learning styles. Despotović-Zrakić et al. [30] presented a tool for adapting the Moodle LMS course material on the basis of a learner's learning preference, to which a data mining technique based on the K-means clustering algorithm was applied. Learners could be clustered into three groups on the basis of their behavior during a one-week period of using the LMS. Each cluster was a subset of FSLSM defined preferences.

Graf et al. [31], [32] introduced a rule-based data mining technique for extracting learning styles from an LMS as a mapping between the FSLSM and learners' online behavior in an LMS [17]. For this experiment, they examined the generic features of an LMS rather than a particular product. In Table 3, grey cells represent the irrelevant patterns or behaviors for each FSLSM learning style. The remaining cells are relevant patterns or behaviors to at least one dimension pair. The "+" and "-" symbols indicate a high and low occurrence, respectively, for each learning style. For example, when we consider the first behavior pattern (content visit), active learners prefer less content visit than reflective learners because they prefer to first attempt exercises without going through content. Sensing and visual learners also less like to visit content than intuitive and verbal learners; therefore, content visit is negative ("-") for active, sensing, and visual learner. It is positive ("+") for reflective, intuitive, and verbal learners. The content visit pattern is irrelevant for sequential and global learners, as represented by grey cells.

\section{PROPOSED FRAMEWORK}

\section{A. System architecture}

To motivate the learner and thus achieve higher performance in learning, we propose a framework for adaptively changing course materials in response to the learner's learning style. Fig. 1 depicts the system organization.

In the default operating environment, an LMS provides multiple courses to its registered learners. Instructors prepare course contents and upload them to the LMS. A database stores all the contents, including questionnaires.

In addition, a user activities log stores the record of learner access to the course content. The course content, usually a collection of learning objects, is arranged in a pre-determined sequence, and some objects maybe available for access at any time (such as forums). The user access log tables of the database store all user activity information.

We add three new modules to this conventional Moodle system: the learning style monitoring and learning profile creation agent (LLA), expert recommendation agent (ERA), and adaptive content presentation and interface enhancement agent (AIA), designed to facilitate the adaptive functionality to Moodle.

The LLA module has three functions. First, it suggests that the learner participates in an ILS questionnaire, which generates the learner's learning style on the basis of the FSLSM. This information is stored as user profiles in a new learning profile table of the Moodle database. The second function (Learning Preference Estimator) of the LLA estimates each learner's learning profile based on his/her activities performed on the LMS. The third function of the LLA graphically projects the learning preference of a user or number of users, and it is a unique feature of our framework. Another unique feature is the ability to fine tune the conditions for the determination of learning styles. The ERA module executes this task. Once it generates a learning profile for a learner, the AIA module recommends learning materials.

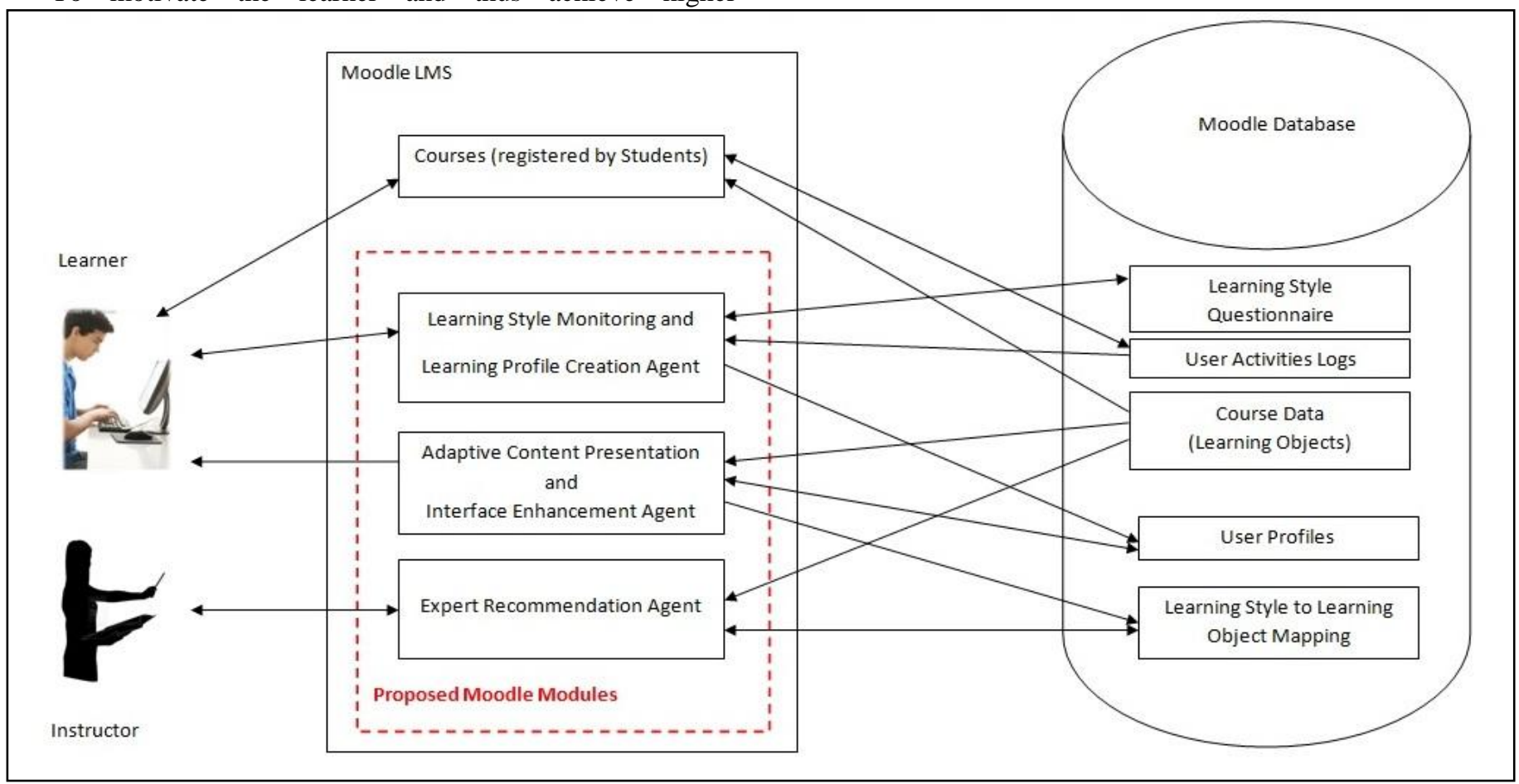

Fig. 1. Proposed framework. 
In the following subsections, we explain each module of the proposed framework in detail.

\section{B. LLA Module}

Once a course instructor adds this module to a course, a learner may choose to complete the ILS questionnaire when he/she starts learning with the system. After the learner completes the questionnaire, his/her learning style preferences are recorded in the database and made available for reference, as depicted in Fig. 2.

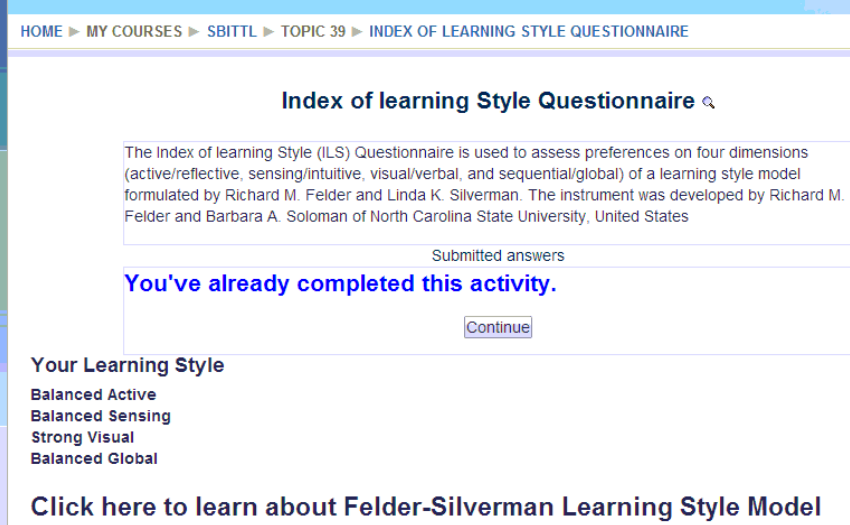

Click here to learn about Felder-Silverman Learning Style Model

Fig. 2. Learning style from ILS Questionnaire.

However, if the learner skips answering this questionnaire, his/her profile is generated by analyzing the log data of how he/she accessed the course material and stored in the learning profile database. This result is also made available for the learner as a reference (Fig. 3).

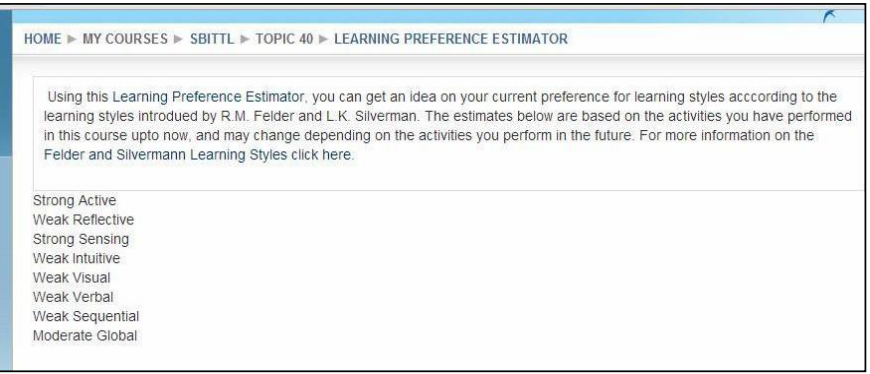

Fig. 3. Learning style from simple rule-based method.

Two records may exist per student. One from the ILS questionnaire, which is usually allowed once per course, whereas the second record, estimated from the activities performed, is updated only on the basis of the learner's activities.

The learning preference estimation is performed upon several factors, as originally presented by Graf and Kinshuk [32], followed by Dung and Florea [33], and explained below. Each LMS course material may contain different learning objects such as videos, quizzes, and exercises. As Table 3 illustrates, the learner's interaction behavior pattern with these objects and the time spent on them can be aligned with certain learning style preferences.

For example, analyzing content-type learning objects (denoted Content Visit in Table 3), it is possible to find out the number of content-type learning objects the learner visited
(LOs VisitedContent $\left._{\text {. }}\right)$. In addition we can also identify the total number of content-type objects in the course $\left(\mathrm{LOs}_{\text {Content }}\right)$ from the Moodle database. These factors constitute the ratio of visits for content-type learning objects ( $\mathrm{R}_{\mathrm{VisitedContent}}$ ):

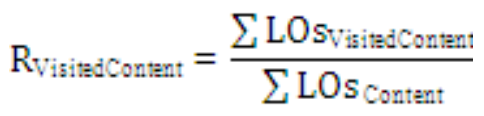

Table 3 reports that the content visiting pattern is associated with three dimensions of the FSLSM. Therefore, this ratio is used when evaluating the learner's preference for the active-reflective, sensing-intuitive, and visual-verbal dimensions.

Similarly, by analyzing time spent on visiting content-type objects (denoted Content Stay Time in Table 3), the instructor or an expert can estimate an expected time to be spent on each learning object $\left(\mathrm{TES}_{\mathrm{Content}}\right)$. From the Moodle log, it is possible to find out the time spent on each content object $\left(\mathrm{TS}_{\text {Content }}\right)$.

The sum of the time values for all content-type learning objects in the course produces the ratio of content stay time $\left(\mathrm{R}_{\text {TimeSpentContent }}\right)$ :

$$
\mathrm{R}_{\text {Tim:SpentContent }}=\frac{\sum \mathrm{TS}_{\text {Content }}}{\sum \mathrm{TES}}
$$

As Table 3 indicates, the content stay time pattern relates to two of the four FSLSM dimensions. Therefore, this ratio is relevant when evaluating the learner's preference for the active-reflective and sensing-intuitive dimensions.

This process is repeated for all behavior patterns, which results in a ratio $\left(\mathrm{R}_{\mathrm{i}}\right)$ for each behavior pattern. For each behavior pattern, $i$, if the ratio lies between a pre-determined upper threshold $\left(\mathrm{UT}_{\mathrm{i}}\right)$ and lower threshold $\left(\mathrm{LT}_{\mathrm{i}}\right)$, the behavior is considered balanced. The values for $\mathrm{UT}_{\mathrm{i}}$ and $\mathrm{LT}_{\mathrm{i}}$ can be adjusted via the ERA module, and the default values considered are those proposed by Graf et al. [34]. If the ratio is less than the lower threshold, the behavior is considered negative. In contrast, if the ratio is higher than the upper threshold, the behavior is considered positive. After performing this process for all behavior patterns, we can calculate the average ratio for each learning style $\left(\mathrm{R}_{\mathrm{AVG}}\right)$ :

$$
\mathrm{R}_{\mathrm{AvG}}=\frac{\sum_{\mathrm{i}=1}^{\mathrm{n}} \mathrm{R}_{\mathrm{i}}}{\mathrm{n}}
$$

where $\mathrm{n}$ is the number of relevant behavior patterns for the selected learning style. This process is repeated for eight learning styles, resulting in the information reported in Table 4. The $\mathrm{R}_{\mathrm{AVG}}$ scores express whether a learner has a weak, moderate, or strong preference for the selected learning style. This classification is performed by using two threshold values, the thresholds for moderate $\left(\mathrm{T}_{\mathrm{M}}\right)$ and strong $\left(\mathrm{T}_{\mathrm{S}}\right)$ preference, where typically $\mathrm{T}_{\mathrm{M}}=0.3$ and $\mathrm{T}_{\mathrm{S}}=0.7$. 
TABLE 4

SAMPLE SCORES ( $\mathrm{R}_{\text {AVG }}$ ) OBTAINED FOR EACH LEARNING STYLE

\begin{tabular}{|c|c|c|c|c|c|c|c|}
\hline \multicolumn{2}{|c|}{ Dimension 1 } & \multicolumn{2}{c|}{ Dimension 2 } & \multicolumn{2}{c|}{ Dimension 3 } & \multicolumn{2}{c|}{ Dimension 4 } \\
\hline ACT & REF & SEN & INT & SEQ & GLO & VIS & VER \\
\hline 0.77 & 0.1 & 0.2 & 0.35 & 0.8 & 0.72 & 0.75 & 0.3 \\
\hline
\end{tabular}

For the above example in Table 4, this analysis would yield the result reported in Table 5, where $S, M$, and $\mathrm{W}$ indicate strong, moderate, and weak, respectively. $\mathrm{T}_{\mathrm{M}}$ and $\mathrm{T}_{\mathrm{S}}$ may need to be fine tuned depending on the content, but that effort remains for a future study.

TABLE 5.

CLASSIFICATION OF LEARNING STYLES ON THE BASIS OF USER PREFERENCE

\begin{tabular}{|c|c|c|c|c|c|c|c|}
\hline \multicolumn{2}{|c|}{ Dimension 1 } & \multicolumn{2}{c|}{ Dimension 2 } & \multicolumn{2}{c|}{ Dimension 3 } & \multicolumn{2}{c|}{ Dimension 4 } \\
\hline ACT & REF & SEN & INT & SEQ & GLO & VIS & VER \\
\hline S & W & W & M & S & S & S & W \\
\hline
\end{tabular}

As the third key facility of the LLA module, the average ratios of each learner can be visualized as a learning preference map. This map is generated by projecting scores pertaining to each dimension for a learner into a quadrant. (Fig. 4). It can also project multiple maps to create an overview of learning preferences for a group of learners.

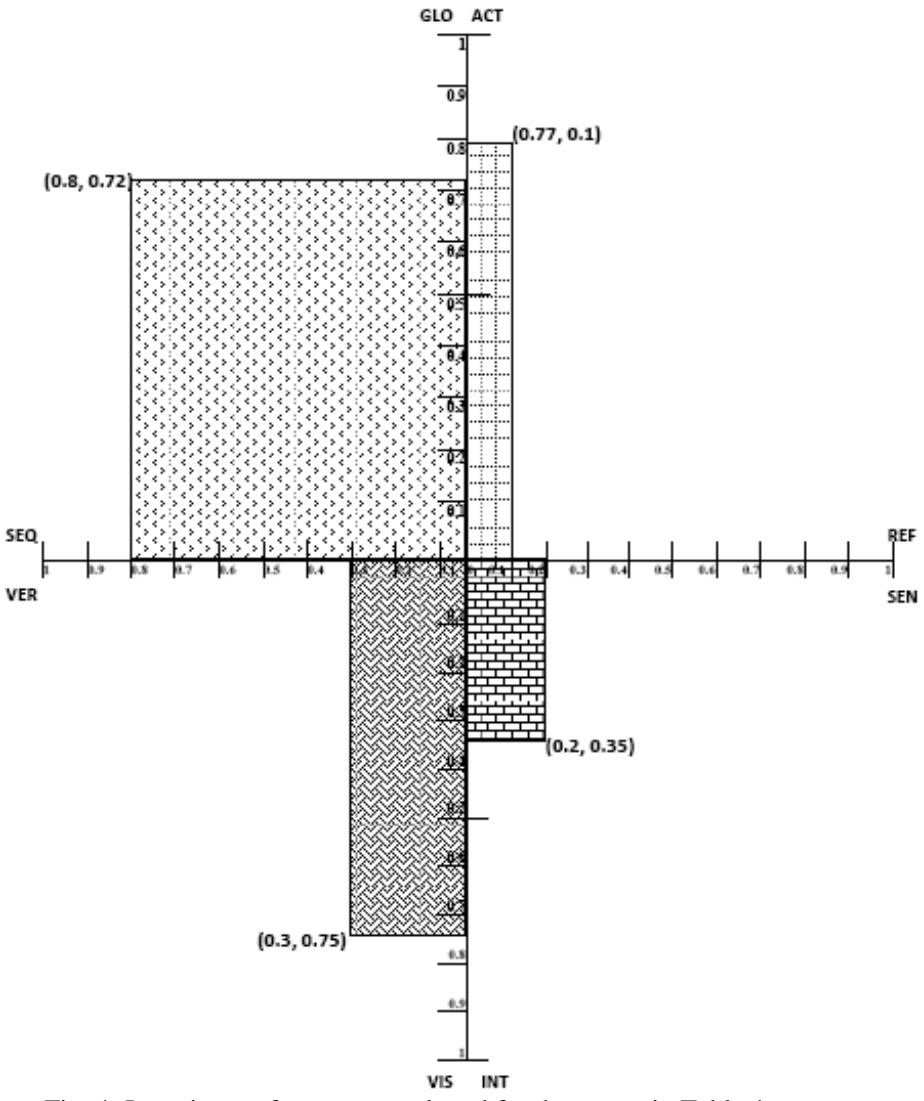

Fig. 4. Learning preference map plotted for the scores in Table 4

\section{ERA Module}

A set of threshold values introduced in the ERA contribute to the estimation of learners' learning styles in the LLA. Apart from $\mathrm{T}_{\mathrm{M}}$ and $\mathrm{T}_{\mathrm{S}}$, sets of upper and lower threshold values figure strongly. As explained in subsection $B$, for each behavior pattern $\mathrm{i}$, two values exist: $\mathrm{UT}_{\mathrm{i}}$ and $\mathrm{LT}_{\mathrm{i}}$. The ERA module is developed for the instructor to adjust the conditions for determining learning styles. Using this interface, the instructor can modify the $\mathrm{UT}_{\mathrm{i}}$ and $\mathrm{LT}_{\mathrm{i}}$ values of all behavior patterns identified in Table 3. The values are given as percentages as Fig. 5 illustrates.

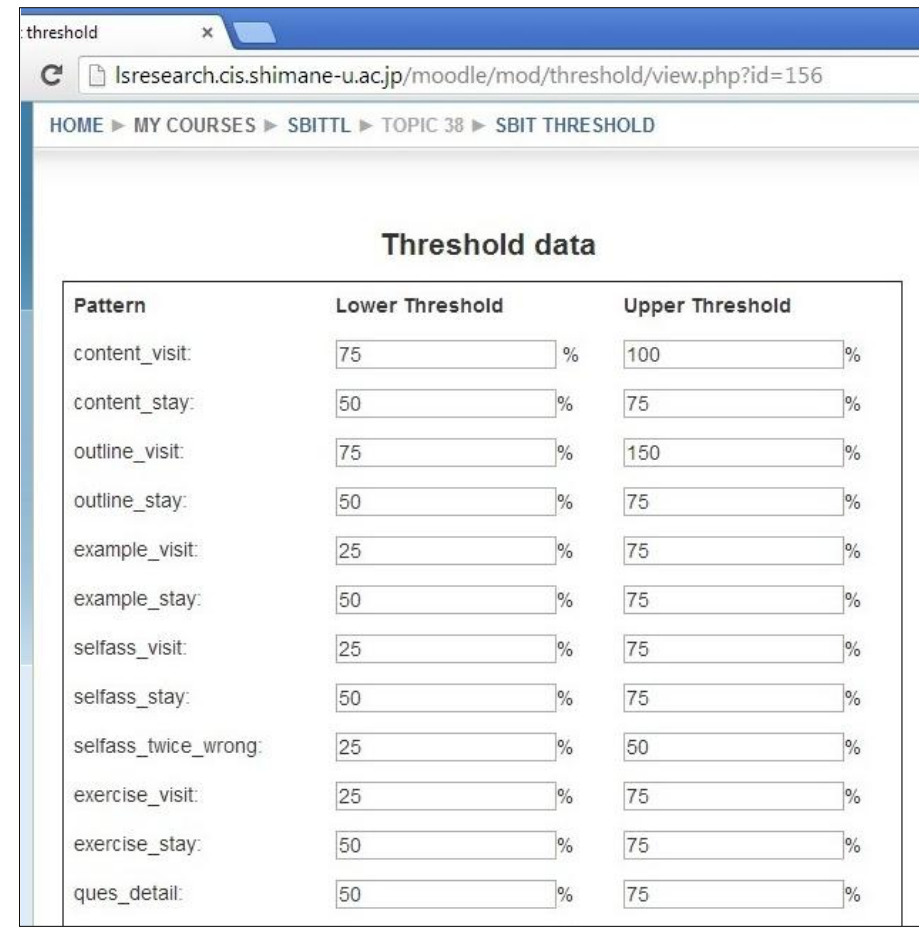

Fig. 5. Threshold data.

Only instructors can see the ERA module, whereas all instructors of the course and learners can access the LLA module.

\section{AIA Module}

We structure our recommendation for the learner by introducing a matrix of the learning styles of each dimension. Tables 6-9 present the recommendation guidelines formulated through our survey of related research [16], [17], [33].

TABLE 6.

LEARNING STYLES TO LEARNING OBJECT (ACTIVITY) MAPPING FOR DIMENSION 1

\begin{tabular}{|c|c|}
\hline Active & Reflective \\
\hline $\begin{array}{l}\text { - Self-assessment tests } \\
\text { - Chat, forum posting } \\
\text { - Multiuser mind map tools } \\
\text { - Multiple choice questions } \\
\text { - Guessing exercises }\end{array}$ & $\begin{array}{l}\text { - Outline of lecture/session } \\
\text { - Case studies } \\
\text { - Slide shows } \\
\text { - Forum viewing } \\
\text { - Using online help } \\
\text { - Content viewing } \\
\text { - Examples } \\
\text { - Single-user mind map tool } \\
\text { - Summaries of lecture/session } \\
\text { - Result pages view }\end{array}$ \\
\hline
\end{tabular}


TABLE 7.

LEARNING STYLES TO LEARNING OBJECT (ACTIVITY) MAPPING FOR DIMENSION 2

\begin{tabular}{|l|l|}
\hline \multicolumn{1}{|c|}{ Sequential } & \multicolumn{1}{c|}{ Global } \\
\hline - Detailed questions & - Outline of lecture/session \\
- Step-by-step exercises & - Lecture/session summaries \\
- Pages with few links & - Pages with multiple links \\
& - Overview questions \\
& - Navigation skip \\
& - Navigation overview pages \\
\hline
\end{tabular}

TABLE 8.

LEARNING STYLES TO LEARNING OBJECT (ACTIVITY) MAPPING FOR DIMENSION 3

\begin{tabular}{|c|c|}
\hline Visual & Verbal \\
\hline $\begin{array}{l}\text { - Graphics } \\
\text { - Tables } \\
\text { - Flowcharts, charts } \\
\text { - Images } \\
\text { - Demonstrations/videos } \\
\text { - Colored or highlighted text } \\
\text { - Slides with multimedia and } \\
\text { animations }\end{array}$ & $\begin{array}{l}\text { - Text-based material } \\
\text { - Audio objects } \\
\text { - Lesson objectives and Content } \\
\text { objects } \\
\text { - Text slideshows with audio }\end{array}$ \\
\hline
\end{tabular}

TABLE 9.

LEARNING STYLES TO LEARNING OBJECT (ACTIVITY) MAPPING FOR DIMENSION 4

\begin{tabular}{|l|l|}
\hline \multicolumn{1}{|c|}{ Sensing } & \multicolumn{1}{c|}{ Intuitive } \\
\hline - Examples & - Content viewing \\
- Exercises & - Questions about concepts \\
- Self-assessment tests & - Concepts and theories \\
- Questions about facts & - Definitions \\
- Detail questions & - Algorithms \\
- Hands-on activities & \\
- Practical material & \\
- Slideshows & \\
- Case studies & \\
\hline
\end{tabular}

However, recommendations are not given for all cases because some do not make sense. Although the basic principle of the ILS is to identify dimensions where the learner is "out of balance," i.e., he/she has a very strong preference for one style and dislikes the others, the opportunity exists for giving conditional recommendations in certain other situations.

We introduce two conditional thresholds for this purpose: the conditional thresholds for strong $\left(\mathrm{CT}_{\mathrm{S}}=\mathrm{T}_{\mathrm{S}}-\mathrm{T}_{\mathrm{M}}=0.4\right)$ and conditional thresholds for moderate $\left(\mathrm{CT}_{\mathrm{M}}=\mathrm{T}_{\mathrm{M}}=0.3\right)$ situations where the two learning style levels are adjoined. Suppose, for a given dimension, the level of learning style 1 (element on one side) is moderate, and that of learning style 2 (element on another side) is weak; if their learning style levels are separated by a score of more than $\mathrm{CT}_{\mathrm{M}}$, we decide to recommend materials relevant to learning style 1 .

TABLE 10.

RECOMMENDATION MATRIX FOR A GIVEN LEARNING STYLE

\begin{tabular}{|c|c|c|c|c|}
\hline & \multicolumn{3}{|c|}{ Learning Style 2 Level } \\
\hline & & Weak & Moderate & Strong \\
\hline \multirow{3}{*}{ 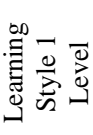 } & Weak & NR & LS2* & LS2 \\
\hline & Moderate & $\underline{\mathrm{LS}} 1 *$ & NR & $\underline{\mathrm{LS} 2^{+}}$ \\
\hline & Strong & LS1 & $\mathrm{LS}^{+}$ & NR \\
\hline
\end{tabular}

Table 10 shows the recommendations to be provided for each pair of learning styles in a certain dimension i (i can be 1-4). LS1 denotes learning style 1 and LS2 denotes learning style 2; for example, for dimension 1, LS1 is active and LS2 is reflective. NR indicates that no recommendation is possible. An underlined item denotes a conditional recommendation. Situations where $\mathrm{CT}_{\mathrm{M}}$ is used are denoted by an asterisk (*), whereas those where $\mathrm{CT}_{\mathrm{S}}$ is used are denoted by a plus sign (+).

The AIA module is currently under development and will be reported on a future date.

\section{EXPERIMENTS}

\section{A. Setup and Procedure}

The system is set up on an Intel Core i5 computer running Windows 7. A WAMP Server (Apache 2.2.21, MySQL 5.5.20, PHP 5.3.10) runs a Moodle 2.3.2 installation.

The system provides a facility to add metadata for learning materials such as outlines, contents, examples, self-assessments, and exercises. This metadata enable an automatic search of the type of content that the learner has accessed. For example, if it is a self-assessment of Chapter 8, the name of the learning material can be any name, and instructor is prompted to select the object type as self-assessment (Fig. 6).

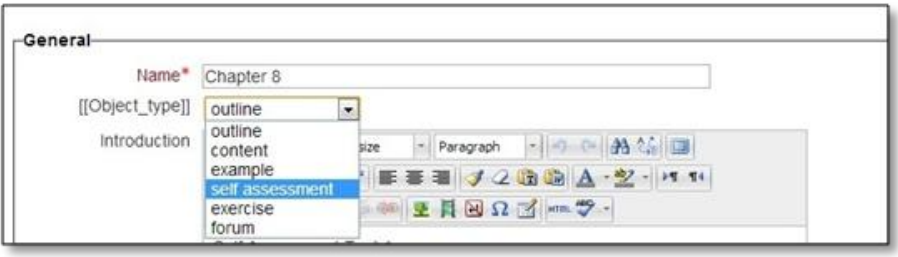

Fig. 6. Adding learning material of different types.

A similar interface mechanism is provided for identifying metadata for questions in quizzes. The instructor specifies the type of question (detail, overview, facts, concepts, graphic, text, interpretation, or developmental) by selecting an appropriate item from a pull down menu. These metadata are stored with the question in the database.

We conducted experiments using two learner groups at two educational establishments in Sri Lanka. The introductory level course content (syllabus) was similar in both institutions. Fig. 7 depicts the main course content screen for the course. The pilot study involved 22 students who enrolled for a course on Introduction to Information Technology in one education establishment. The second trial involved 80 students from the second educational establishment. The course spanned fourteen weeks during a single semester.

Here the learning materials were prepared to match the course content. An important consideration was to make the content redundant in various media forms: text, slideshows, animations, video, and audio. The course content contained a total of 50 learning material items comprising 22 content objects, 8 outlines, 2 flash examples, 10 self-assessment quizzes, and 8 exercise quizzes. Content object video tutorials were packaged as SCORM material.

We tested the LLA functionality of our framework by comparing the predicted learning styles (LLA functionality) 
against the results obtained by using the ILS questionnaire. For each dimension, we calculated the percentage of learners whose preference was accurately predicted by our framework.

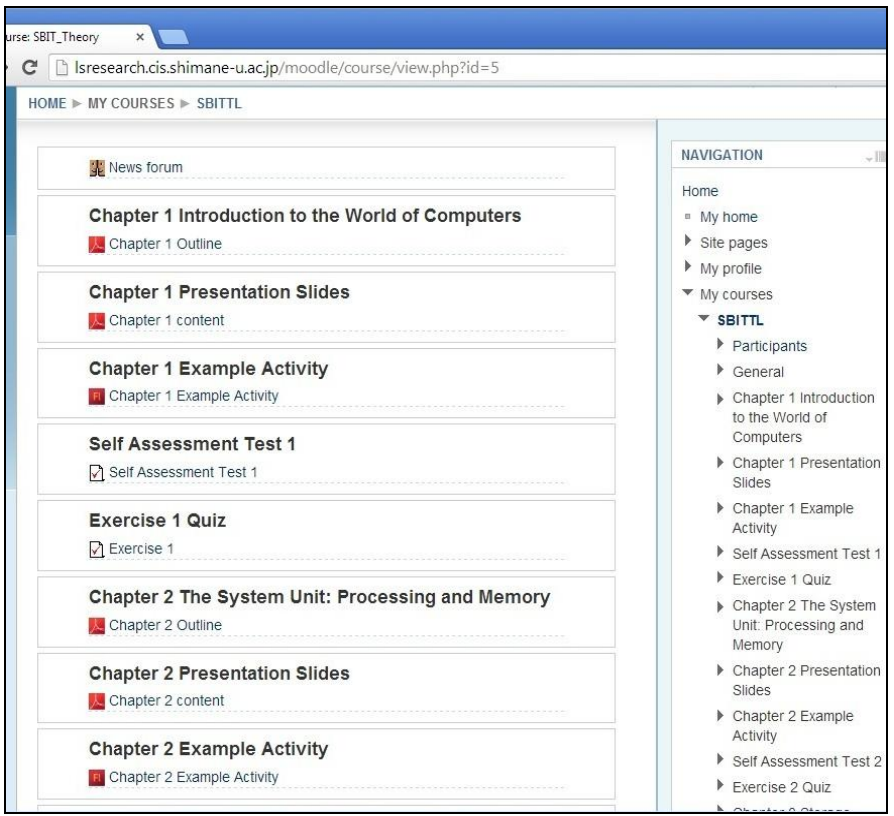

Fig. 7. Course content.

\section{B. Results and Discussion}

To evaluate our performance, we used the precision measurement proposed by Garcia et al. [9]. If the magnitude of the learning style obtained by the ILS ( $\mathrm{LS}_{\mathrm{ILS}}$ ) was equal to the learning style estimate of our framework $\left(\mathrm{LS}_{\mathrm{FW}}\right)$, we considered Sim in the following formula to be 1,0 if they are opposite, and 0.5 if one is neutral and the other is an extreme value. A parameter $\mathrm{n}$ represents the number of students who followed the course.

$$
\text { Precision }=\frac{\sum_{\mathrm{i}=1}^{\mathrm{n}} \operatorname{Sim}\left(\mathrm{LS}_{F \mathrm{w}}, \mathrm{LS}_{\mathrm{ILS}}\right)}{\mathrm{n}} \times 100
$$

Garcia et al. [9] calculated the precision for a course on Artificial Intelligence followed by 40 students. They used a data mining method employing Bayesian Networks for estimation of the learning styles. Graf et al. [12] estimated learning styles using a simple rule based method for a course on Web Engineering followed by 43 students. Dung and Florea [33] used a simple rule based method for estimating learning styles on a course in Artificial Intelligence followed by 44 students. The precision rate obtained in our two trials is comparable to the results obtained by the researchers mentioned above, as Table 11 reports. However, the conditions of calculating the precision rate may not be exactly the same across trials.

In both trials we conducted, the Active/Reflective dimension precision is slightly lower than the rates in other dimensions, as well as the corresponding rates obtained by some of the other researchers. A possible reason for this is that, in our trials, face-to-face content delivery sessions (i.e. traditional classroom lectures) were provided in conjunction with LMS learning sessions. In addition, a text handbook in print accompanied the course content. This would have created a situation where some students might have no compelling reason to refer to the LMS content material. We are currently fine tuning our thresholds and calculation system to further improve our method's precision.

TABLE 11.

PRECISION RATE COMPARISON

\begin{tabular}{|c|c|c|c|c|}
\hline Authors & ACT/REF & SEN/INT & VIS/VER & SEQ/GLO \\
\hline $\begin{array}{c}\text { Garcia et al. } \\
{[9]}\end{array}$ & $58.00 \%$ & $77.00 \%$ & - & $63.00 \%$ \\
\hline $\begin{array}{c}\text { Graf et al. } \\
{[12]}\end{array}$ & $79.33 \%$ & $77.33 \%$ & $76.67 \%$ & $73.33 \%$ \\
\hline $\begin{array}{c}\text { Dung and } \\
\text { Florea[33] }\end{array}$ & $72.73 \%$ & $70.15 \%$ & $79.54 \%$ & $65.91 \%$ \\
\hline $\begin{array}{c}\text { This study } \\
\mathbf{1}^{\text {st }} \text { trial }\end{array}$ & $\mathbf{6 3 . 6 4 \%}$ & $\mathbf{7 7 . 2 7 \%}$ & $\mathbf{7 2 . 7 3 \%}$ & $\mathbf{7 7 . 2 7 \%}$ \\
\hline $\begin{array}{c}\text { This study } \\
\mathbf{2}^{\text {nd }} \text { trial }\end{array}$ & $\mathbf{6 5 . 0 0 \%}$ & $\mathbf{7 5 . 0 0 \%}$ & $\mathbf{7 6 . 2 5 \%}$ & $\mathbf{7 7 . 5 0 \%}$ \\
\hline
\end{tabular}

\section{CONCLUSIONS AND FUTURE WORK}

This study introduces a new framework for detecting learners' learning style in an LMS. The framework is based on the FSLSM and has been implemented on a Moodle LMS. Our two trials reveal that the system is comparable with previous studies when considering the learning profile creation. We are currently in stage II of our system development, which involves presenting content based on the learner's profile. We also plan to compare our present results using the simple rule-based approach with approaches that utilize sophisticated data mining techniques. Currently, 700 students use our proposed system, and we will report the data analysis for these students at a future date with the AIA module.

Finally, we also aspire to embed learning style preference for SCORM content, which would allow the content to be reused without needing to re-tag content for its learning style preference.

\section{REFERENCES}

[1] Alias N. A., and Zainuddin A. M. (2005). Innovation for better teaching and learning: Adopting the learning management system. Malaysian Online Journal of Instructional Technology, 2(2): 27-40.

[2] (2014) Moodle Learning Management System [Online]. Available: http://www.moodle.org.

[3] (2014) Blackboard Educational Technology Platforms [Online]. Available: http://www.blackboard.com

[4] (2014) Sakai [Online]. Available: https://sakaiproject.org/

[5] Graf S. and List B. (2005). An evaluation of open source e-learning platforms stressing adaptation issues. Fifth IEEE International Conference on Advanced Learning Technologies (ICALT'05), Taiwan, IEEE Press, pp. 163-165.

[6] Burgos D. and Specht M. (2006), Adaptive e-Learning Methods and IMS Learning Design: An Integrated Approach, Sixth International Conference on Advanced Learning Technologies (ICALT'06), Kerkrade, Netherlands, pp. 1192-1193.

[7] De Crook M. , Mofers F., Veen M.V., Rosmalen P.V., Brouns F., Boticario J.G., Barrera C., Santos O., Ayala A., Gaudioso E., Hernández F., Arana C., Trueba I., Fuentes C., and Rodrigo M.D.M. (2002). Active learning for adaptive internet - state of the art, project deliverable report. [Online] Available 
[8] Felder R.M. and Silverman L.K. (1988). Learning and Teaching Styles in Engineering Education. Engineering Education, 78 (7): 674-681.

[9] García P., Amandi A., Schiaffino S. S., and Campo M. (2007). Evaluating Bayesian networks precision for detecting students' learning styles. Computers \& Education, 49(3): 794-808.

[10] Graf S. and Kinshuk. (2006). Enabling Learning Management Systems to Identify Learning Styles. Conference ICL, Villach, Austria, 1(9): pp. 1-9.

[11] (2013) Felder R.M., Soloman B.A., Felder-Soloman Index of Learning Styles [Online] Available: http://www4.ncsu.edu/unity/lockers/users/f/felder/public/ILSpage.html

[12] Graf S., Kinshuk, and Liu Tzu-Chien. (2008). Identifying Learning Styles in Learning Management Systems by Using Indications from Students' Behaviour. Proceedings of the IEEE International Conference on Advanced Learning Technologies, Santander, Spain, pp.482-486.

[13] Honey P. and Mumford A. (1992). The Learning Styles Helper's Guide. Peter Honey Publications Ltd., Maidenhead, p.1.

[14] Stewart K. L., and Felicetti L. A. (1992). Learning styles of marketing majors. Educational Research Quarterly, 15(2): 15-23.

[15] Coffield F., Moseley D., Hall E., and Ecclestone K. (2004b). Should We Be Using Learning Styles? What Research Has to Say to Practice? Learning and Skills Research Centre / University of Newcastle upon Tyne, London, pp.1-182.

[16] Kanninen E.S.S.I. (2009). Learning styles in virtual learning environments: Master of Science Thesis, p.64.

[17] Graf S. (2007). Adaptivity in Learning Management Systems Focussing on Learning Styles: Ph.D. Thesis: Vienna University of Technology., p.192.

[18] Myers I.B. (1962). Manual: The Myers-Briggs Type Indicator. Consulting Psychologists Press, Palo Alto, CA.

[19] Kolb A.Y. and Kolb D.A. (2005). The Kolb Learning Style Inventory Version 3.1, Technical Specification, Hay Group, Boston.

[20] Honey P. and Mumford A. (2006). The Learning Styles Helper's Guide. Peter Honey Publications Ltd., Maidenhead.

[21] (2014) Kolb learning styles [Online]. Available: http://www.businessballs.com/kolblearningstyles.htm

[22] Chang Y., Kao W., Chu C., and Chiu C. (2009). Computers \& Education A learning style classification mechanism for e-learning. Computers \& Education, 53(2): 273-285.

[23] Carver C. A., Howard R. A., and Lane W. D., (1999). Adressing different learning styles through course hypermedia. IEEE Transactions on Education, 42(1): 33-38.

[24] Cha H.J., Kim Y.S., Park S.H., Yoon T.B., Jung Y.M., and Lee J.H. (2006). Learning style diagnosis based on user interface behavior for the customization of learning interfaces in an intelligent tutoring system. Proceedings of the 8th International Conference on Intelligent Tutoring Systems, Berlin, Heidelberg, Springer, pp. 513-524.

[25] Surjono H. D. (2014). The Evaluation of a Moodle Based Adaptive e-Learning System, International Journal of Information and Education Technology, 4(1): 89-92.

[26] Savic G. and Konjovic Z. (2009). Learning Style Based Personalization of SCORM E-learning Courses, 7th International Symposium on Intelligent Systems and Informatics, Subotica, Serbia, pp. 349-353.

[27] Park H., Darak-ri I. G., and Chungbuk G. C. (2005). Design and development of a mobile learning management system adaptive to learning style of students. Proceedings of the 2005 IEEE International Workshop on Wireless and Mobile Technologies in Education, IEEE Computer Society Washington, DC, USA, pp. 4-6.
[28] Klasnja-Milicevic A., Vesin B., Ivanovic M., Budimac Z. (2011). E-Learning personalization based on hybrid recommendation strategy and learning style identification. Computers \& Education, 56(3): 885-899.

[29] Ozpolat E., and Akar G.B. (2009). Automatic detection of learning styles for an e-learning system. Computers \& Education, 53(2): 355-367.

[30] Despotović-Zrakić M, Markoviae A., Bogdanoviae A., Baraae D., Sciences O., and Iliaea J. (2012). Providing Adaptivity in Moodle LMS Courses Adaptive e-learning systems. The Journal of Educational Technology \& Society, 15(1): 326-338.

[31] Graf S., Viola S.R., and Kinshuk. (2007). Automatic Student Modelling for Detecting Learning Style Preferences in Learning Management Systems. Proceedings of the International Conference on Cognition and Exploratory Learning in Digital Age, Algarve, Portugal, pp.172-179.

[32] Graf S., and Kinshuk. (2008). Analysing the Behaviour of Students in Learning Management Systems with respect to Learning Styles. Advanced in Semantic Media Adaptation and Personalization, Springer Series on Studies in Computational Intelligence, 93(1): 53-74.

[33] Dung P.Q., and Florea A.M. (2012). An approach for detecting learning styles in learning management systems based on learners' behaviours. International Conference on Education and Management Innovation, IACSIT Press, Singapore, vol. 30, pp. 171-177.

[34] Graf S., and Liu T. (2009). Supporting Teachers in Identifying Students' Learning Styles in Learning Management Systems : An Automatic Student Modelling Approach. Educational Technology \& Society, 12(4): 3-14. 